\title{
Strategi Pengembangan Kerbau Rawa Di Kabupaten Hulu Sungai Utara Kalimantan Selatan
}

\section{(Swamp Buffalo Development Strategy in Hulu Sungai Utara Regency South Borneo)}

\author{
Ahmad Suhaimi ${ }^{1)}$ Rum Van Royensyah ${ }^{2)}$ \& Heldawati ${ }^{3)}$ \\ Program Studi Agribisnis, Sekolah Tinggi Ilmu Pertanian Amuntai \\ 1)ahmad99ec@gmail.com \\ ${ }^{2)}$ Vanroyensyah61@gmail.com \\ ${ }^{3)}$ heldawati006@gmail.com
}

\begin{abstract}
ABSTRAK
Penelitian ini bertujuan untuk mengetahui alternatif strategi pengembangan kerbau rawa di wilayah Hulu Sungai Utara, Kalimantan Selatan. Penelitian ini menggunakan metode survei dengan partisipasi teknik observasi, diikuti dengan analisis LFA (Logical Framework Approach). Hasil penelitian menunjukkan strategi pengembangan kerbau rawa di Desa Sapala Kecamatan Paminggir yaitu meningkatkan penggunaan teknologi tepat guna, mengadakan lomba pacuan rawa kerbau, meningkatkan keterampilan partisipasi masyarakat, peran penyuluh dan pemerintah, pembinaan / penyuluhan dari instansi terkait, menambah modal, meningkatkan operasi hubungan kerja antara bisnis, peternakan yang dekat dengan jaringan transportasi, serta meningkatkan penggunaan lahan dengan pemuliaan yang baik, dan meningkatkan kinerja kelembagaan.
\end{abstract}

Kata kunci: Strategi, pengembangan, kerbau, rawa, LFA.

\section{ABSTRACT}

This study aims to determine an alternative development strategy swamp buffalo in the region of Hulu Sungai Utara, South Borneo. This study uses survey method participation premises observation techniques, followed by analysis of the LFA (Logical Framework Approach). The results showed strategy development swamp buffalo in the Sapala Village Paminggir Districts namely increasing the use of appropriate technologies, held a contest races swamp buffalo, increase community participation skills, the role of extension workers and government, guidance / counseling from relevant agencies, increase capital, improve working relationships operation between businesses, farms made close to transport links, as well as improving land use with good breeding, and improve institutional performance.

Keywords: Strategy, development, buffalo, swamp, LFA.

\section{PENDAHULUAN}

Kalimantan Selatan merupakan salah satu propinsi yang memiliki potensi pengembangan peternakan yang lebih baik dibanding ketiga propinsi lain di Kalimantan. Di Kalimantan Selatan terdapat empat lokasi rawa banjir yang dimanfaatkan untuk peternakan kerbau rawa (Bubalus bubalis) dengan sistem kalang, yakni di Kabupaten Hulu Sungai Utara, Hulu Sungai Tengah, Hulu Sungai Selatan dan Barito Kuala. Populasi ternak kerbau rawa yang paling banyak adalah di Kabupaten Hulu Sungai Utara berjumlah 7.771 ekor yang tersebar di Desa Palbatu, Bararawa, Ambahai, Sapala, Tampakang dan Paminggir, Kecamatan Paminggir.
Pemeliharaan kerbau pada umumnya masih dilakukan secara tradisonal di tempattempat khusus, yang belum banyak mendapatkan campur tangan manusia, misalnya di areal sungai, semak belukar, pinggir hutan, rawa-rawa dan lain-lain (Suryana dan Hamdan, 2010).

Di Kalimantan Selatan, kerbau rawa memberikan kontribusi positif sebagai penghasil daging, terutama untuk daerah pedalaman pada agroekosistem rawa dengan kedalaman air 3-5 m. Kerbau rawa merupakan ternak asli daerah dan sumber plasma nutfah dan telah dikembangkan sebagai usaha tani spesifik lokasi pada agroekosistem lahan rawa. Ternak ini juga memiliki peranan penting dalam kehidupan 
sosial ekonomi masyarakat sebagai sumber pendapatan dan tabungan keluarga peternak. Hal ini didukung dengan luas wilayah Kalimantan Selatan 3.753.052 ha, dengan luasan lahan rawa sekitar 181.169 ha atau $4,83 \%$ dari luas wilayah yang dimiliki merupakan potensi yang prospektif dalam rangka pengembangan dan melestarikan ternak kerbau rawa di Kalimantan Selatan (Suryana \& Handiwirawan, 2007).

Populasi ternak besar yang paling banyak di Kabupaten Hulu Sungai Utara adalah kerbau, padatahun 2011 kerbau di Kabupaten Hulu Sungai Utara hanya berjumlah 7.813 ekor terjadi penurunan jumlah populasi yang sangat besar dari 6 tahun terakhir yaitu sebanyak 873 ekor. Penurunan populasi pada tahun 2011 dikarenakan tingginya angka pemotongan ternak dan kematian ternak kerbau. Kematian ternak tersebut dikarenakan wilayah Kabupaten Hulu Sungai Utara dilanda musim hujan yang berkepanjangan sehingga menyebabkan pakan kesukaan kerbau tidak dapat tumbuh dengan baik dan sebagian besar membusuk di dalam air.

Penelitian ini dilakukan dengan tujuan untuk mengetahui pihak-pihak mana yang terkait dalam pegembangan kerbau rawa, faktor eksternal dan internal pengembangan kerbau rawa, masalah utama dalam pengembangan kerbau rawa serta tujuan akhir yang ingin dicapai dalam pengembangan kerbau rawa. Dan mengetahui alternatif strategi yang dapat diterapkan dalam mengembangkan kerbau rawa di Desa Sapala Kecamatan Paminggir Kabupaten Hulu Sungai Utara.

\section{METODE PENELITIAN}

\section{Tempat dan Waktu Penelitian}

Penelitian ini dilaksanakan di Desa Sapala Kecamatan Paminggir Kabupaten Hulu Sungai Utara. Waktu penelitian dilaksanakan mulai bulan Maret - Agustus 2014.

\section{Jenis dan Sumber Data}

Data yang dikumpulkan terdiri dari data primer dan data sekunder. Data primer diperoleh langsung wawancara dengan peternak kerbau rawa dengan menggunakan daftar pertanyaan yang sudah disiapkan. Data sekunder diperoleh dari instansiinstansi yang terkait serta studi pustaka dari berbagai media yang berhubungan dengan penelitian ini.

\section{Metode Penelitian}

Penelitian ini menggunakan metode survei dengan teknik Observasi Partisipasi, dimana Metode Observasi Partisipasi adalah observasi yang melibatkan peneliti atau observer secara langsung dalam kegiatan pengamatan di lapangan. Jadi, peneliti bertindak sebagai observer, artinya peneliti merupakan bagian dari kelompok yang ditelitinya.

\section{Metode Pengumpulan Data}

Responden dalam penelitian ini adalah peternak kerbau, responden ditentukan dengan menggunakan rumus Slovin (1996), yaitu :

Dimana :

$$
n=\frac{N}{1+N e^{2}}
$$

$\mathrm{n}=$ banyaknya responden / sampel

$\mathrm{N}=$ banyaknya populasi

$\mathrm{e}=$ error $/$ ketidaktelitian $(10 \%)$

Populasi sebanyak 85 orang dimasukkan ke dalam rumus dengan tingkat ketidak-telitian sebesar $10 \%$, maka didapatkan responden sebanyak 46 orang.

\section{Analisis Data}

Analisis data dilakukan dengan LFA terdiri dari beberapa analisis, yang pertama yaitu analisis stakeholder, analisis SWOT, analisis pohon masalah dan analisis tujuan.

\section{HASIL DAN PEMBAHASAN}

\section{Analisis LFA \\ Hasil Penelitian \\ Analisis Stakeholder}

Pihak-pihak yang berperan sebagai stake holder dalamp engembangan kerbau rawa adalah sebagai berikut :

a. Peternak kerbau

Peternak kerbau rawa merupakan pelaku utama yang merupakan titik tolak keberhasilan dari pengembangan kerbau 
rawa ini. Banyak yang dilakukan peternak dalam pengembangan kerbau rawa ini dimulai dari pembuatan kandang kerbau atau yang disebut kalang, pembelian bibit, pemeliharaan, sampai dengan penjualan kepada pengumpul atau bisa juga langsung menjual kepada pemotong kerbau yang ada di pasar Alabio dan Amuntai diharapkan agar harga kerbau bisa lebih tinggi.

b. Investor

Adalah salah satu sumber dana penunjang pengembangan kerbau rawa di Sapala, kebanyakan investor ini orang-orang dari luar daerah dimana mereka membeli kerbau dan akan diserahkan kepada salah satu peternak untuk memelihara kerbau tersebut. Peternak akan mendapat keuntungan jika kerbau sudah beranak, pembagian hasil diberikan atas kesepakatan kedua belah pihak.Ketertarikan investor untuk menanam modal kepada peternak dalam membantu mengembangkan usaha ternak kerbau rawa karena usaha tersebut menjanjikan keuntungan kedua belah pihak.

c. Bank

Salah satu sumber dana yang dapat menunjang keberlangsungan sebuah usaha yang dijalankan, bantuan dalam bentuk kredit pinjaman uang. Untuk para peternak kerbau rawa yang ada di desa Sapala, dari pihak bank sendiri yang berinisiatif untuk memberikan pinjaman kepada para peternak, tetapi para peternak tidak mau menerima bantuan dengan alasan tidak ingin terikat dengan lembaga simpan pinjam.

d. Kelompok Ternak Kerbau Rawa

$\begin{array}{ccc}\text { Merupakan } & \text { gabungan dari para } \\ \text { peternak yang melalukan kegiatan }\end{array}$

peternakan kerbau rawa, kelompok ternak di Desa Sapala ini tidak secara resmi dibentuk. Para peternak berinisiatif sendiri untuk bermusyawarah sesama peternak jika terdapat masalah dalam pengelolaan usaha ternak dari masing-masing peternak. Para peternak dapat berbagi informasi, memecahkan masalah, pembentukan modal serta sebagai jembatan permasalahan dari peternak kepada pemerintah untuk mengembangkan usahanya.

e. Universitas/PerguruanTinggi

Peternak bisa menjalin kerjasama dengan universitas terkait saling bertukar informasi, universitas bias melakukan penelitian terhadap usaha peternak kerbau rawa dan peternak bias memperoleh informasi yang belum diketahuinya dari universitas. Dan diharapkan universitas tersebut bias memberikan masukan atau pengadaan obatobatan untuk ternak kerbau rawa jika sewaktu-waktu kerbau ada yang sakit.

\section{Analisis SWOT \\ AnalisisMatriks SWOT}

Setelah dilakukan analisis lingkungan internal dan eksternal maka dilakukan proses pemaduan antara elemen kekuatan, kelemahan, peluang dan ancaman dengan matriks SWOT. Tujuan dari pemanduan ini adalah untuk menentukan alternative strategi yang dipilih. Dari hasil matriks SWOT dapat diperoleh beberapa strategi alternative dalam Pengembangan Agribisnis Usaha kerbau Rawa di Desa Sapala yang dapat diuraikan pada Tabel 1 berikut ini: 
Tabel 1. Matriks SWOT Pengembangan Agribisnis Kerbau Rawa di Desa Sapala Kecamatan Paminggir Kabupaten Hulu Sungai Utara.

\begin{tabular}{|c|c|c|}
\hline Eksternal & $\begin{array}{l}\text { Kekuatan (S) } \\
\text { 1. Wilayah yang luas untuk kegiatan } \\
\text { usaha ternak kerbau rawa } \\
\text { 2. } \begin{array}{l}\text { Perubahan iklim tidak } \\
\text { mempengaruhi proses pemeliharaan } \\
\text { ternak kerbau rawa }\end{array} \\
\text { 3. } \begin{array}{l}\text { Menjadikan Usaha UtamaPemilik } \\
\text { 4. Adanya regenerasi yang meneruskan } \\
\text { usaha peternakan (turun temurun) }\end{array} \\
\text { 5. Keahlian Terampil Dan } \\
\text { Berpengalaman } \\
\text { 6emasaran yang Mudah }\end{array}$ & $\begin{array}{l}\text { Kelemahan (W) } \\
\text { 1. Ketersediaan Hijauan Pakan Ternak } \\
\text { Sangat Dipengaruhi Oleh Musim } \\
\text { 2. Sistem usaha tani masih Sederhana } \\
\text { dan tradisional } \\
\text { 3. Kurang Optimalnya Kelembagaan } \\
\text { yang Ada (Kelompok, Koperasi atau } \\
\text { Lainnya) } \\
\text { Kurangnya keahlian di dalam } \\
\text { penanganan hasil } \\
\text { Modal terbatas, hanya menggunakan } \\
\text { modal sendiri } \\
\text { 6ematian Anak Relatif Tinggi }\end{array}$ \\
\hline \begin{tabular}{ll} 
& \multicolumn{1}{c}{ Peluang $(\mathrm{O})$} \\
1. & Permintaan daging meningkat \\
2. & Pengembangan Objek Wisata \\
3. & Peluang Kerja Masyarakat \\
4. & Perkembangan Teknologi Yang \\
& Semakin Maju
\end{tabular} & \begin{tabular}{|l}
\multicolumn{1}{c}{ Strategi S-O } \\
1. \\
Meningkatkan penggunaan teknologi \\
maju baik dari semua sudut. \\
2. $\begin{array}{l}\text { Setiap tahun diadakan lomba pacuan } \\
\text { kerbau rawa } \\
\text { 3. }\end{array}$ \\
Meningkatkan peranserta masyarakat \\
pemerintah agar usaha ternak dapat \\
berjalan dengan baik.
\end{tabular} & \begin{tabular}{|l} 
Strategi W-O \\
1. \\
$\begin{array}{l}\text { Pembinaan/penyuluhan dari instansi } \\
\text { terkait yang lebih intensif dalam hal } \\
\text { budidaya dan kelembagaan. }\end{array}$ \\
2. $\begin{array}{l}\text { Meningkatkan permodalan untuk } \\
\text { membantu dalam pengembangan } \\
\text { usaha. }\end{array}$
\end{tabular} \\
\hline 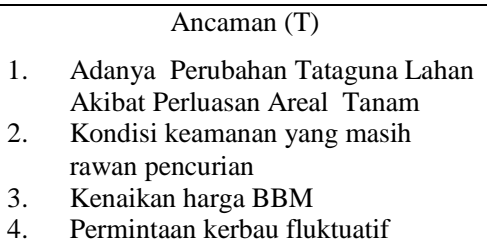 & $\begin{array}{l}\text { Strategi S-T } \\
\text { 1. Meningkatkanhubungankerjasamaant } \\
\text { 2. } \begin{array}{l}\text { arpelakuusaha. } \\
\text { Lokasikalangdibuatdekatdenganjalurt }\end{array}\end{array}$ & $\begin{array}{l}\text { Strategi W-T } \\
\text { 1. Meningkatkan tataguna lahan } \\
\text { peternakan dengan baik } \\
\text { 2. Memperbaikikinerjakelembagaan }\end{array}$ \\
\hline
\end{tabular}

\section{Bagan Keterkaitan Masalah}

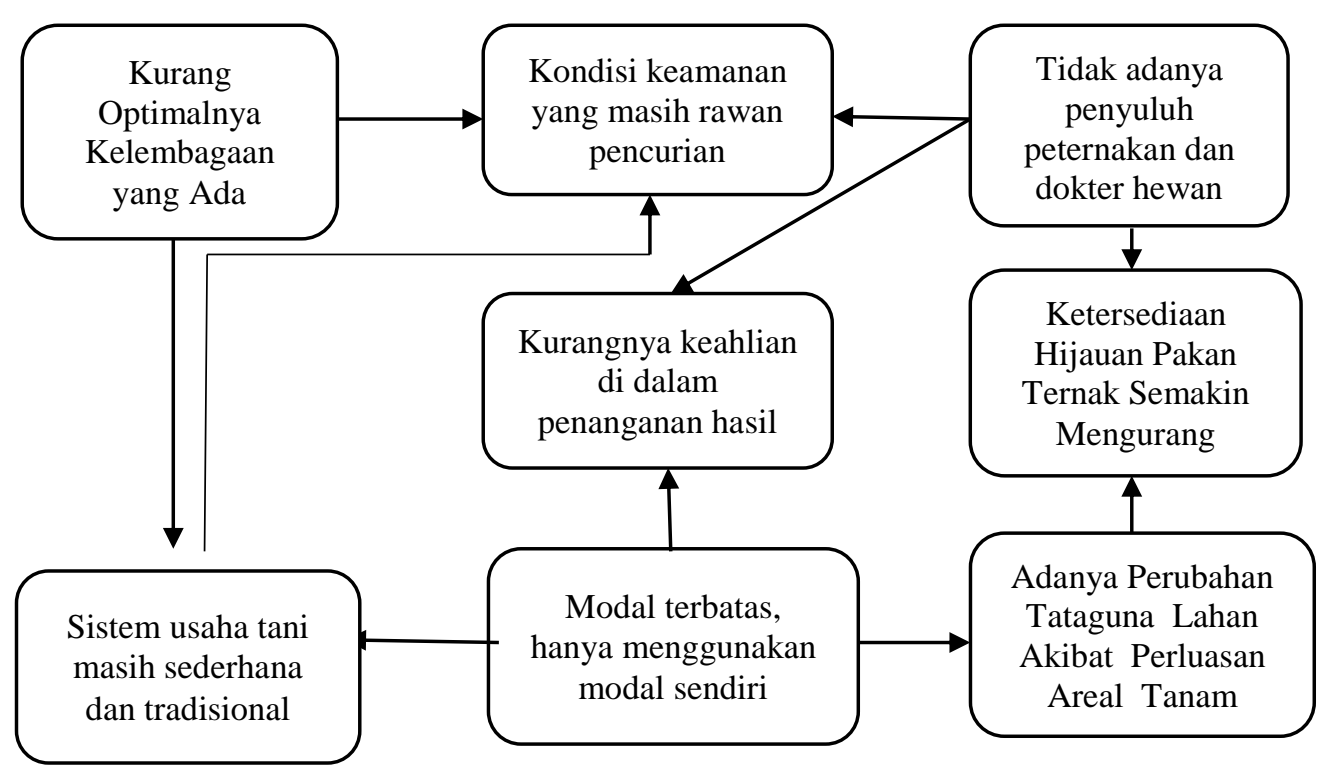

Gambar 1. Keterkaitan Permasalah Pengembangan Usaha kerbau rawa di Desa Sapala Kecamatan Paminggir Kabupaten Hulu Sungai Utara 


\section{Hasil Logical Framework Analysis (LFA)}

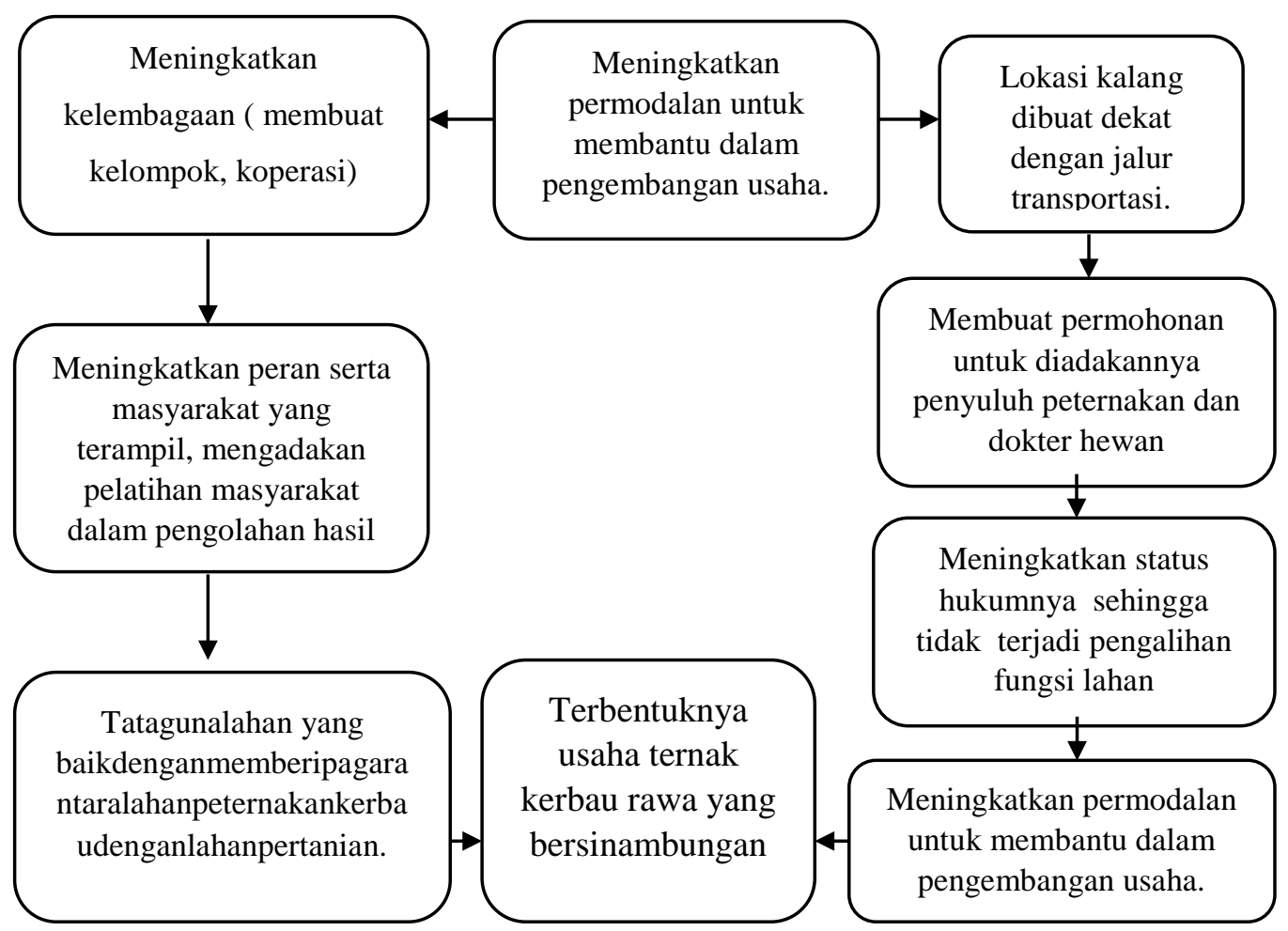

Gambar 2. Keterkaitan Strategi pengembangan Usaha kerbau rawa di Desa Sapala Kecamatan Paminggir Kabupaten Hulu Sungai Utara

\section{Pembahasan}

\section{Analisis Stakeholder}

Dari hasil penelitian ini, ditetapkan pihak-pihak yang berperan sebagai stakeholder dalam usaha pengembangan ternak kerbau rawa di desa Sapala kecamatan Paminggir yaitu peternak kerbau rawa, investor, bank, kelompok ternak kerbau rawa, dan universitas/perguruan tinggi.

\section{Analisis SWOT}

Analisis

SWOT yang

dilakukanterdapat faktor eksternal dan internal. Faktor internal usaha kerbau rawa terdiri dari kekuatan dan kelemahan, kekuatan diantaranya adalah 1) wilayah yang luas untuk ternak kerbau rawa, 2) perubahan iklim yang tidak mempengaruhi proses pemeliharaan ternak kerbau rawa, 3) menjadikan usaha utama pemilik, 4) adanya regenerasi yang meneruskan usaha peternakan, 5) keahlian terampil dan berpengalaman, 5) pemasaran yang mudah. Faktor kelemahan yaitu: 1) ketersediaan pakan ternak dipengaruhi oleh musim, 2) sistem usaha tani masih sederhana dan tradisional, 3) kurang optimalnya kelembagaan, 4) kurangnya keahlian dalam penanganan hasil, 5) modal terbatas, 6) kematian anak relatif tinggi. Faktor eksternal usaha kerbau rawa di Desa Sapala terdiri dari peluang dan ancaman yaitu: peluang 1) permintaan daging meningkat, 2) pengembangan objek wisata, 3) peluang kerja masyarakat, 4) Perkembangan teknologi yang semakin maju. Ancaman 1) adanya perubahan tataguna lahan akibat perluasan areal tanam, 2) kondisi keamanan yang masih rawan pencurian, 3) Kenaikan harga BBM 4), Permintaan kerbau fluktuatif.

\section{Analisis Pohon Masalah (Problem Tree)}

Hasil penelitian ini menunjukkan ada 3 kelompok utama yang menjadi penyebab kurang berkembangnya usaha 
pengembangan kerbau rawa di desa Sapala kecamatan Paminggir yaitu berkurangnya pakan ternak di alam, keterbatasan modal usaha dan tidak adanya penyuluh peternakan dan dokter hewan yang ditugaskan di Desa Sapala.

\section{Analisis Tujuan}

Tujuan yang diharapkan dalam penelitian ini adalah adanya pengembangan usaha ternak kerbau rawa di desa Sapala yang terpadu dan terencana sehingga pemecahan masalah dapat teratasi dengan tepat dan cepat yaitu dengan cara ketersediaan modal, kemudahan peminjaman modal, banyak permintaan kerbau rawa, tersedia sarana dan prasaran, terjaminnya mutu peralatan atau fasilitas pembibitan, adanya kelompok usaha terpadu, SDM yang terampil dalam usaha ternak kerbau rawa, peternak mampu beradaptasi dengan profesi barunya, ketersediaan ahli teknologi budidaya teknologi, adanya informasi kondisi wilayah, pemanfaatan areal budidaya secara optimal.

\section{KESIMPULAN}

Berdasarkan hasil analisis LFA, yang pertama analisis stakeholder yaitu pihakpihak yang berperan sebagai stakeholder dalam pengembangan kerbau rawa di desa Sapala kecamatan Paminggir adalah peternak kerbau rawa, investor, bank, kelompok ternak kerbau rawa dan universitas/perguruan tinggi. Analisis yang kedua yaitu analisis SWOT yang digunakan untuk pengembangan kerbau rawa, dimana dalam analisis SWOT terdapat faktor eksternal dan internal. Faktor internal usaha kerbau rawa terdiri dari kekuatan dan kelemahan, kekuatan diantaranya adalah wilayah yang luas untuk ternak kerbau rawa, perubahan iklim yang tidak mempengaruhi proses pemeliharaan ternak kerbau rawa, menjadikan usaha utama pemilik, adanya regenerasi yang meneruskan usaha peternakan, keahlian terampil dan berpengalaman, pemasaran yang mudah. Faktor kelemahan yaitu: ketersediaan pakan ternak dipengaruhi oleh musim, sistem usaha tani masih sederhana dan tradisional, kurang optimalnya kelembagaan, kurangnya keahlian dalam penanganan hasil, modal terbatas, kematian anak relatif tinggi. Faktor eksternal usaha kerbau rawa di Desa Sapala terdiri dari peluang dan ancaman yaitu: peluangpermintaan daging meningkat, pengembangan objek wisata, peluang kerja masyarakat, Perkembangan teknologi yang semakin maju. Ancaman adanya perubahan tataguna lahan akibat perluasan areal tanam, kondisi keamanan yang masih rawan pencurian, Kenaikan harga BBM, Permintaan kerbau fluktuatif.

Analisis yang ketiga yaitu analisis pohon masalah/problem tree, ada 3 kelompok utama yang menjadi penyebab kurang berkembangnya usaha pengembangan kerbau rawa di desa Sapala yaitu berkurangnya pakan ternak di alam, keterbatasan modal usaha dan tidak adanya penyuluh peternakan dan dokter hewan yang ditugaskan di desa Sapala. Analisis yang keempat yaitu analisis tujuan, dimana terdapat purpose dan result.

Dari keempat analisis tersebut dapat diperoleh strategi pengembangan kerbau rawa di desa Sapala kecamatan Paminggir yaitu meningkatkan penggunaan teknologi tepat guna, mengadakan lomba pacuan kerbau rawa, meningkatkan peran serta masyarakat yang terampil, peran penyuluh dan pemerintah, pembinaan/penyuluhan dari instansi terkait, meningkatkan permodalan, meningkatkan hubungan kerja sama antar pelaku usaha, lokasi kalang dibuat dekat dengan jalur transportasi, serta meningkatkan tataguna lahan peternakan dengan baik, dan memperbaiki kinerja kelembagaan.

1) Peternak dapat meningkatkan keterampilan budidaya kerbau rawa sesuai petunjuk teknis dari pemerintah dan meningkatkan kegiatan promosi, memanfaatkan perkembangan teknologi dan perluasan pasar agar komoditas yang terjual semakin meningkat dan diversifikasi hasil ternak kerbau.

2) Pemerintah daerah atau pihak swasta dapat memberi bantuan, pelatihan dan 
Ahmad Suhaimi, Rum Van Royensyah \& Heldawati, Strategi pengembangan kerbau rawa...

mempromosikan komoditas lokal yang berkelanjutan.

3) Harus ada penyuluh peternakan dan dokter hewan yang ditugaskan di desa Sapala agar usaha peternakan kerbau rawa menjadi berkembang dengan baik.

\section{DAFTAR PUSTAKA}

Suryana dan Handiwirawan, E. 2007. Daya Dukung Lahan Rawa Sebagai Kawasan Sentra Pengembangan Kerbau Kalang Di Kalimantan Selatan. Seminar Nasional dan Lokal karya Usaha ternak Kerbau. Balai Pengkajian Teknologi Pertanian Kalimantan Selatan dan Pusat Penelitian dan Pengembangan Peternakan.

Suryana dan Hamdan. 2010. Potensi Lahan Rawa Di Kalimantan Selatan Untuk Pengembangan Peternakan Kerbau. Lokal karya Nasional Usaha Ternak Kerbau Mendukung Program Kecukupan Daging Sapi. Balai Pengkajian Teknologi Pertanian Kalimantan Selatan. 